\title{
O cerco multidimensional à Teerã e a aproximação Sino-Iraniana
}

\author{
Diego Pautasso, Tiago Soares Nogara, \\ Augusto Gabriel Colório e Victor Leão Wobeto
}

Resumo: O artigo visa esclarecer como o cerco multidimensional a Teerã, liderado pelos Estados Unidos e seus aliados, incidiu sobre o processo de aproximação sino-iraniano. Neste contexto, a China impulsionou suas relações com o Irã sem comprometer seus interesses estratégicos junto a Washington e Riad. Em suma, o custo de impor sanções ao Irã pode ser a precipitação de novos alinhamentos de poder, em benefício da estratégia de ascensão global chinesa.

Palavras-chave: China. Irã. Estados Unidos. Sanções.

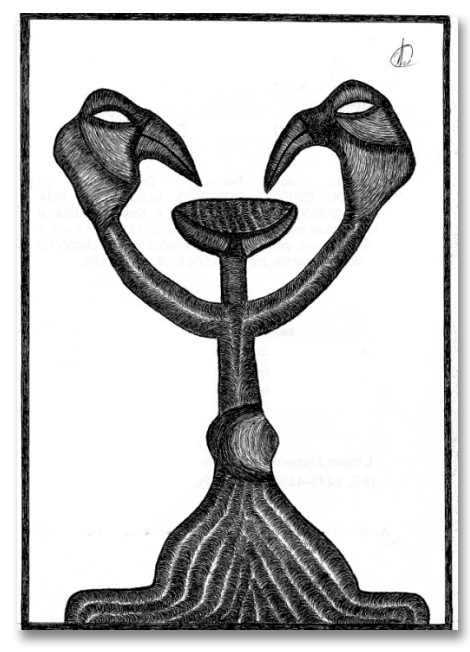

\section{Diego Pautasso}

Doutor em Ciência Política pela Universidade Federal do Rio Grande do Sul (UFRGS). Professor do Colégio Militar de Porto Alegre.

E-mail: dgpautasso@gmail.com

\section{Tiago Soares Nogara}

Mestrando do Programa de Pós-Graduação em Relações Internacionais (PPGRI), da Universidade de Brasília (UnB).

E-mail: tiagosnogara@gmail.com

\section{Augusto Gabriel Colório}

Mestrando em Conflito e Segurança Internacional pela Universidade de Kent e graduado em Relações Internacionais pela Unisinos.

E-mail: augustocolorio@hotmail.com

\section{Victor Leão Wobeto}

Graduando em História da

Universidade Federal de Santa

Catarina (UFSC).

E-mail: victorlwobeto@gmail.com

\section{The multidimensional siege of Tehran and Sino-Iranian relations}

Abstract: The article aims to clarify how the multidimensional siege of Tehran, led by the United States and its allies, contributes to Sino-Iranian relations. In this context, China boosted its relations with Iran without compromising its strategic interests with Washington and Riyadh. The cost of imposing sanctions on Iran may precipitate new power alignments, in benefit of China's global rise strategy.

Keywords: China. Iran. United States. Sanctions.

RECEBIDO: 27/01/2019

APROVADO: 10/09/2019 
Diego Pautasso, Tiago Soares Nogara, Augusto Gabriel Colório E Victor LeÃo Wobeto

\section{Introdução}

Os atentados de 11 de setembro de 2001 provocaram um redirecionamento da política externa dos Estados Unidos e, quiçá, um momento de aceleração histórica das mudanças sistêmicas. A diplomacia estadunidense recrudesceu seu expansionismo com a invasão ao Afeganistão, em 2001, e depois ao Iraque, em 2003, legitimadas pela doutrina Bush, pela guerra global ao terror e pela política do ataque preventivo (YORDAN, 2006). Tratou de levar a cabo a rivalidade contra o Eixo do Mal (Cuba, Coreia do Norte, Irã, Iraque, Líbia e Síria), países já definidos como rivais prioritários desde o Project for the New American Century (PNAC), publicado em 19971. Após estas intervenções, seguiu-se o cerco multidimensional ao Irã, aprofundado a partir de 2005, sob pretexto da eleição do primeiro ministro Mahmoud Ahmadinejad. Naturalmente, num cenário de isolamento e hostilidade, o governo iraniano fortaleceu seu programa nuclear, enquanto os Estados Unidos moveram seus aliados e parte da comunidade internacional para a imposição de sanções econômicas e ameaças de emprego da força contra o país médio-oriental.

Além de não coadunar estritamente com a política dos Estados Unidos, Beijing aproveitou-se do cerco promovido a Teerã para impulsionar o relacionamento bilateral. Nesse sentido, o artigo visa mapear as motivações da evolução das relações sino-iranianas no período entre o acirramento das sanções, multilaterais e unilaterais, e a assinatura do Acordo Nuclear (Joint Comprehensive Plan of Action - JCPOA), em 2015. Sugere-se como hipótese principal que, ao impor o cerco ao Irã, os Estados Unidos acabaram por fortalecer as relações do país médio-oriental com a China, que buscou, a um só tempo, atrair os iranianos para sua órbita e consentir seletivamente com sanções multilaterais no âmbito do Conselho de Segurança da ONU, voltadas a limitar a proliferação nuclear. Desse modo, o trabalho busca contribuir não apenas para a compreensão da evolução das relações sino-iranianas no

1 O PNAC se transformou em um think tank e ofereceu os principais quadros e linha política da administração de Bush filho. Para ver detalhes, vale ler as publicações da organização, disponíveis em: <http://www. newamericancentury.org/publicationsreports.htm>. Acesso em: 20 out. 2019. 
contexto das sanções, mas também para a iluminação de temas pertinentes à política externa dos Estados Unidos, a rivalidade destes com a China e as correntes mudanças no balanço de poder no Oriente Médio e na Eurásia, sobretudo no contexto da iniciativa chinesa de integrar a região através da Nova Rota da Seda. Sem dúvida, tal dinâmica ajuda a dar inteligibilidade aso papeis de Estados Unidos e China na região, num quadro de acelerada emergência de novas configurações de poder.

Sendo assim, na primeira seção, será abordado o processo pelo qual os Estados Unidos construíram não apenas as sanções, mas um cerco multidimensional ao Irã no quadro mais geral de sua política externa. Na segunda seção, apresentar-se-á um breve histórico das relações entre Beijing e Teerã. Na última seção, será analisado o pragmatismo chinês no contexto do isolamento iraniano, permitindo aprofundamento da relação bilateral ao tempo em que preserva os interesses do país junto à Washington e Riad.

\section{A ambivalência ocidental diante do programa nuclear iraniano: do alinhamento político ao cerco multidimensional}

Para compreender a ambivalência dos Estados Unidos e seus aliados diante do programa nuclear do Irã, é preciso pontuar algumas questões. Primeiro, as relações dos Estados Unidos e seus aliados com o Irã têm revelado oscilações no padrão de rivalidade. No pós-guerra, o país herdeiro do milenar império persa figurava como um potencial aliado ocidental até o início dos anos 1950, quando o Majlis, parlamento iraniano, determinou, em 1951, a nacionalização do complexo petrolífero da Anglo-Iranian Oil Company (AIOC), de origem britânica. Valendo-se das técnicas de covert action, a Agência Central de Inteligência (CIA) e o M16 desenvolveram a Operação Ajax, visando à desestabilização de Mossadegh. O general Zahedi, por consequência, destituiu o então líder nacionalista e primeiro-ministro, através de um golpe militar, e implantou uma monarquia dirigida pelo xá Reza Pahlavi, executando imediatamente lideranças do Tudeh, comunista, e do Partido Nacional. O governo do xá manteve estrito alinhamento com os Estados Unidos, como atesta a participação na aliança 
Diego Pautasso, Tiago Soares Nogara, Augusto Gabriel Colório E Victor LeÃo Wobeto

militar de 1955, via Pacto de Bagdá - posteriormente rebatizada de Organização do Tratado Central (CENTO) -, junto ao Iraque, ao Paquistão, à Turquia e ao Reino Unido. Foi nesse contexto, de Guerra Fria, em que o Irã recebeu apoio de Washington para desenvolver seu programa nuclear, com o acordo de cooperação de 1957 - ampliado em 1969. O Irã teria rápida adesão, em 1970, ao Tratado de Não-Proliferação de Armas Nucleares (TNP), ratificando, em 1974, o Acordo de Salvaguardas da Agência Internacional de Energia Atômica (AIEA) (DORRAJ; CURRIER, 2008).

Após a crise do petróleo de 1973, decorrente da articulação da Organização de Países Exportadores de Petróleo (OPEP) diante dos eventos da Guerra de Yom Kippur, as potências ocidentais ampliaram seus laços com o governo iraniano, cooperando de forma intensa para o desenvolvimento de seu programa nuclear, já que este permitia a ampliação do excedente de recursos fósseis para exportações do país. Neste contexto, a alemã Kraftwerk Union (KWU) dirigiu a construção da usina atômica de Bushehr, estabelecendo compromisso de repasse de dois reatores da Siemens. Em 1975, a França iniciou os planos de construção de um centro de treinamento para cientistas da área nuclear em Isfahan. Ainda em 1974, o Irã investiu na construção de uma planta comercial de enriquecimento de urânio, a ser controlada pelo consórcio Eurodif. Por fim, em 1978, os Estados Unidos da América fecharam um importante acordo com o Irã, comprometendo-se a fornecer oito reatores nucleares e vender combustível nuclear e tecnologias para as atividades de pesquisa iranianas, com exceção daquelas consideradas sensíveis, vinculadas ao enriquecimento e reprocessamento de urânio (LAMPREIA, 2014). Alinhados com o bloco estadunidense, países como África do Sul e Israel também cooperaram com o programa nuclear, com o primeiro provendo urânio natural e o segundo assistência técnica. A companhia francesa Framatome construiu, em seguida, a segunda central nuclear do país, desta vez em Darkhovin. Portanto, somente com a revolução islâmica de 1979 os Estados Unidos cessaram sua cooperação nas atividades nucleares do país persa, levando Teerã a mobilizar esforços próprios e a se voltar para países como Paquistão e, posteriormente, China e Rússia (LAMPREIA, 2014). 
Após a revolução de 1979, o Irã não sofreu apenas com sanções unilaterais e multilaterais, mas com um crescente cerco multidimensional, motivado por questões geopolíticas. Os incidentes com diplomatas estadunidenses, ainda no quadro da revolução, motivaram a primeira onda de sanções, por meio do congelamento de ativos de cidadãos iranianos nos Estados Unidos e a interrupção das importações de petróleo. A rivalidade recrudesceu diante da subsequente Guerra Irã-Iraque (1980- 1988), quando a política externa de Washington modificou seus alinhamentos regionais.

A segunda onda de sanções estadunidenses à Teerã ocorreu em 1984, quando a base dos Estados Unidos em Beirute foi atacada por um grupo de militantes chamado Jihad Islâmica - acusado de ser parte do Hezbollah e financiado pelo Irã. Apregoando aos iranianos a incitação de operações terroristas, tais sanções incluíram uma variedade de temas, dentre eles a restrição da assistência norte-americana, a proibição de venda de armas e o controle na exportação de produtos com uso duplo, utilizados tanto para fins pacíficos quanto para fins militares (LAUB, 2015).

Apenas a terceira onda de sanções unilaterais foi motivada pela questão nuclear. Em meados dos anos 1990, foi intensificado um embargo econômico total contra empresas, de qualquer nacionalidade, que se relacionassem com o Irã nas áreas de petróleo e gás. No início do século XXI, pressões sobre o Irã buscavam sua adesão ao Protocolo Adicional ao Acordo de Salvaguardas, garantindo à AIEA a inspeção, com um pré-aviso de mínima antecedência, de todo local considerado suspeito, a fim de obter informações concretas referentes ao seu programa nuclear.

O E3 - França, Alemanha e Grã-Bretanha - evitou que a AIEA solicitasse intervenção do Conselho de Segurança, reiterando os interesses destes países em manter seus importantes laços comerciais, importantes para suas respectivas seguranças energéticas, com o Irã. Ainda em 2003, o E3 chegaria a um acordo com Teerã, garantindo a suspensão do enriquecimento e reprocessamento de urânio no país, além da implementação do Protocolo Adicional. Neste acerto, o Irã obteria reconhecimento dos seus direitos às pesquisas nucleares, além da disponibilidade das potências europeias para fornecer acesso à tecnologia necessária 
ao desenvolvimento de seu programa, desde que com finalidades pacíficas. No entanto, o acordo de 2003 não foi ratificado pelo parlamento iraniano e o impasse foi mantido (LAMPREIA, 2014).

É preciso considerar que o início do século XXI, depois da eleição de George W. Bush e dos atentados de 11 de setembro, foi remodelada política externa dos Estados Unidos. A direita americana ampliou seu poder e conseguiu dar relevância ao Project for the New American Century, desencadeando a guerra global ao terror, após a queda das Torres Gêmeas. O intervencionismo no Afeganistão e no Iraque estavam articulados às novas diretivas estratégicas e assentadas na noção de preemptive attacks, prioritariamente focados no considerado Eixo do Mal. Além disso, se somavam à política de regime change, tanto no Cáucaso quanto no Oriente Médio, campanhas de kill/capture, o assassinato seletivo por meio de drones e intervenções humanitárias/R2P (BANDEIRA, 2005, 2013, 2016). No Grande Oriente Médio, seriam ampliadas a complexidade das questões securitária face aos acontecimentos da Primavera Árabe, a partir de 2011 - com destaque para o colapso da Líbia, a guerra civil da Síria e a desestabilização de inúmeros países na conturbada região.

Diante desse convulsivo quadro regional, a diplomacia estadunidense intensificou, a partir da eleição do primeiro ministro Mahmoud Ahmadinejad, em 2005, as pressões sobre Teerã, alegando fraude no pleito, e ampliou as investidas contra seu programa nuclear. Também em 2005, a AIEA aprovou resolução na qual decretava a falta de evidências acerca dos fins pacíficos do programa nuclear iraniano. Apesar das adversidades, o Irã manteve o enriquecimento de urânio enquanto resistia às investidas internacionais capitaneadas por Washington. Entre 2006 e 2010, a comunidade internacional aprovou três resoluções, via Conselho de Segurança, que buscavam impedir o desenvolvimento do programa nuclear iraniano. Mesmo que tais restrições visassem especialmente os setores militares, elas colocavam como possibilidade sua expansão para os setores financeiros e da indústria de energia. Nesse ínterim, a União Europeia aprovou o embargo ao setor petrolífero do Irã, com considerável efeito negativo para a economia do país. Além do embargo total de 2012, Bruxelas também 
impediu o acesso dos bancos iranianos ao SWIFT'2, isolando o país do sistema financeiro e, por extensão, do comércio internacional.

A chamada Dual Track Strategy abriu nova etapa de negociações, com o $\mathrm{P} 5+1^{3}$ propondo o fornecimento de tecnologias para o programa nuclear civil, em troca do estabelecimento de maior controle da AIEA sobre o mesmo. Negociações com o P5+1 foram realizadas em Genebra, em 2009, chegando-se a um pré-acordo entre as partes, segundo o qual o Irã enviaria à Rússia $1.200 \mathrm{~kg}$ de urânio levemente enriquecido (LEU), a ser transformado em combustível para o reator de pesquisa de Teerã. Novamente, após robusta oposição interna, o Irã foi obrigado a derrubar o acordo. Conseguintes negociações com o P5+1, desta vez em Viena, tiveram os iranianos declarando que aceitariam trocar urânio por combustível nuclear, mas as potências condicionaram isso a uma imediata suspensão das atividades do programa. Negando-se a paralisa-las, Teerã passou a produzir urânio enriquecido em 20\%, gerando o auge da crise diplomática.

Foi neste contexto de crise que surgiu a articulação da Declaração de Teerã, em 2010, envolvendo Brasil e Turquia, reafirmando o compromisso dos países com o TNP, ou seja, com o desenvolvimento de energia nuclear para fins pacíficos, e estabelecendo a participação da AIEA na sua formulação. Apesar dos avanços nas conversas trilaterais, os países do Conselho de Segurança não endossaram as formulações das mesmas, gerando o fracasso da Declaração. Em fevereiro de 2013, durante encontro em Almaty, no Cazaquistão, o P5+1 ofereceu uma série de concessões ao Irã, como a redução das sanções ligadas às exportações de ouro e produtos petroquímicos, em troca da aceitação, por parte dos iranianos, do limite de 20\% para o enriquecimento do urânio (LAMPREIA, 2014).

Observando em perspectiva, não restam dúvidas de que, apesar dos pretextos de apoio a grupos insurgentes e desenvolvimento

2 Ver reportagem de Gladstone e Castle (2012).

3 Grupo constituído pelos cinco membros permanentes do Conselho de Segurança das Nações Unidas (China, Estados Unidos, França, Reino Unido e Rússia) mais a Alemanha. 
de atividades ilícitas junto ao programa nuclear, as sanções ao Irã decorrem de suas transformações domésticas e alinhamentos internacionais. Kissinger (2015, p. 140) deixa claro que a Arábia Saudita tem "navegado entre os marcos fixos da amizade com os Estados Unidos" e buscado "fortalecer sua própria posição" para fazer frente ao Irã. De forma semelhante, Washington conduz com extremo cuidado as relações com Riad, de modo a evitar a convulsão doméstica/regional e, pior, um equilíbrio de poder no Oriente Médio amparado em potências extra regionais, como China e Rússia (KISSINGER, 2015). Sintetizando essas implicações, o que preocupa Washington não é a nuclearização em si do Irã, e não só porque foi apoiador do programa nuclear no passado, ou porque Israel, Índia e Paquistão são potências nucleares sem adesão ao TNP, mas devido à condição iraniana de potência regional não-alinhada. Ou seja, a lógica motivadora do cerco não é a capacitação militar-nuclear do Irã em si, tampouco as suas disfunções institucionais - certamente menores do que as do governo saudita.

Para alcançar seus objetivos, Washington não mobiliza apenas sanções econômicas, mas um cerco multidimensional, baseado também em ameaças de emprego da força, intervenções em países vizinhos, chantagens diplomáticas e cerco militar. Uma análise do quadro geopolítico permite observar a ocorrência de fenômenos como as intervenções militares operadas em países vizinhos, o fortalecimento de aliados estadunidenses portadores de armas nucleares, como Israel, ou de significativa capacidade militar, vide Arábia Saudita, e a degradação da situação política e social do entorno regional, imerso em eventos como a guerra civil da Síria, as "revoluções coloridas" da Geórgia e do Quirguistão e, ainda, a intervenção não-declarada de potências regionais no Iêmen. Losurdo (2010) destaca que, além de estabelecerem um cerco ao Irã, os embargos e as sanções constituem punições coletivas contra a população civil do país.

Apesar da sistemática tentativa dos Estados Unidos e seus aliados isolarem o Irã, este país conseguiu resistir, preservar sua soberania, estabelecer novos aliados e, ainda, assinar um acordo que não representou uma capitulação, o Joint Comprehensive Plan 
of Action (JCPOA), de 2015. Por um lado, Teerã se comprometeu a aceitar determinadas regras, mas sem abrir mão de seu programa nuclear ou das tecnologias necessárias para a produção de energia e, evidentemente, para o desenvolvimento de seu poder dissuasório. Por outro lado, Washington aceitou esse desfecho em razão de diversas questões superpostas, incluindo os compromissos políticos domésticos de Obama, a ineficácia das políticas de embargo e ameaças ao Irã e a necessidade de influenciar a participação iraniana na guerra da Síria, em favor dos interesses ocidentais. De todo modo, como reconhece a publicação do think tank RAND Corporation, o aumento da pressão dos Estados Unidos sobre o Irã levou o país ainda mais para os braços de Beijing (HAROLD; NADER, 2012), e certamente isso influenciou a assinatura do acordo de 2015.

\section{Do antagonismo à cooperação: a progressiva aproximação entre Irã e China}

No cenário da Guerra Fria, China e Irã emergiram, nos anos 1950, em lados opostos da contenda. Enquanto os chineses prestavam apoio, juntos aos soviéticos, ao partido comunista iraniano, o Tudeh, o Irã de Reza Pahlavi se somava aos Estados Unidos no teatro de operações da Guerra da Coreia. Nesse contexto, o ocidentalizado comando iraniano opôs-se à admissão da República Popular da China na ONU, apoiando a manobra para manter a República da China, Taiwan, como herdeira do Império do Meio. Somente em 1967, reconheceria a China continental e declararia, em 1969, apoio ao pleito de Beijing para ocupar a cadeira de membro permanente do Conselho de Segurança da ONU - no lugar de Taipei. Essa aproximação decorria de novos eventos, como o cisma sino-soviético e a ambiguidade da política estadunidense no Grande Oriente Médio, levando ambas as nações a buscarem maior autonomia diante do cenário bipolar (DORRAJ; CURRIER, 2008).

A partir da revolução de 1979, as relações sino-iranianas se intensificaram. Embora Beijing mantivesse certa neutralidade em eventos como a Guerra Irã-Iraque (1980-1988), dois acontecimentos importantes marcaram a convergência de posições 
sino-iranianas: a condenação à invasão soviética no Afeganistão e o respaldo iraniano à postura chinesa frente aos protestos na Praça da Paz Celestial. Terminado o conflito com os iraquianos, intensificaram-se os laços bilaterais, evidenciados na disposição chinesa de contribuir para os esforços de reconstrução da infraestrutura iraniana e para o provimento de tecnologia e armamentos. Diante da negativa da Kraftwerk Union em retomar os trabalhos em Bushehr, durante a Guerra Irã-Iraque, o Irã buscou cooperação com companhias da França, da Argentina e da Espanha, ao mesmo tempo em que contatava potenciais supridores de novos reatores para pesquisa, como China, Índia e URSS (GAIETTA, 2015). As pressões diplomáticas dos Estados Unidos sobre atores como Bonn, Buenos Aires e Nova Délhi foram efetivas, obstruindo possível diálogo de cooperação (LAMPREIA, 2014). Nesse contexto, após visita oficial de Hashemi Rafsanjani a Pequim, foi formalizada, em 1985, a cooperação nuclear entre China e Irã. O protocolo assinado entre os países previa a venda, por parte dos chineses, de três pequenos reatores para pesquisa. Nos anos subsequentes, a China garantiria o treinamento e qualificação da força de trabalho iraniana vinculada às pesquisas, prestando significativo apoio para a criação do Centro de Pesquisas Nucleares de Isfahan, de vital importância no desenvolvimento do programa nuclear iraniano (HAROLD; NADER, 2012). Mesmo com a Rússia tendo acordado a reconstrução do reator de Bushehr, progressivamente, a China se tornaria a principal parceira persa em cooperações nucleares, posição que manteria, pelo menos, até 1994 (GAIETTA, 2015).

Em 1993, o acelerado crescimento econômico chinês tornou o país um importador líquido de petróleo, aumentando sua demanda por suprimento energético. Isso foi determinante para impulsionar as relações tanto com o Irã quanto com outros importantes exportadores de petróleo, caso da Arábia Saudita. Porém, as disputas no Estreito de Taiwan, em 1996, fizeram Beijing recuar seus níveis de assistência à Teerã, temendo maior acirramento em sua relação com Washington. Um efetivo aprofundamento das relações sino-iranianas avançou a partir do início da década de 2000, sobretudo após o recrudescimento das sanções (HAROLD; NADER, 2012). 
No começo do século XXI, a posição da China foi de evitar o acirramento das disputas entre Washington e Teerã. Beijing buscava se esquivar da utilização de sanções e pressões sobre Teerã, favorecendo a adoção de soluções pacíficas (HUA, 2006). Apesar disso, o país aderiu às sanções internacionais, mesmo que de forma tardia, visando conter a proliferação nuclear e evitar um espraiamento do conflito entre Estados Unidos e Irã, bem como eventual desestabilização do Oriente Médio. Ao mesmo tempo, a diplomacia chinesa trabalhou ativamente para bloquear resoluções que pudesse impor limitações às exportações de hidrocarbonetos (HONG, 2014). Em suma, a China conciliava com Washington no plano diplomático, mas preservava seus interesses econômicos junto à Teerã.

Além da preocupação chinesa com sua segurança energética, o Irã passou a ter significativa importância no contexto de ascensão da Nova Rota da Seda (One Belt, One Road), anunciada por Beijing em 2013, e transformada num grande fórum em 20174. Na visita do presidente Xi Jinping ao Irã, em janeiro de 2016, foi ressaltada a cooperação para a promoção desse monumental projeto, além de assinados dezessete acordos de cooperação entre os dois países ${ }^{5}$.

Ao ser analisado em perspectiva histórica, o caso do Irã replica situações nas quais Beijing buscou explorar brechas e contradições deixadas pela política externa da Casa Branca. O caso do continente africano é emblemático, pois a China concentrou grande esforço diplomático para firmar presença num continente marginalizado no processo de globalização pós-Guerra Fria (MONTE, 2010). No mesmo sentido, a diplomacia chinesa tem se aproximado de países rivais de Washington, como aqueles pertencentes ao considerado Eixo do Mal ou sob intervenção. Na Venezuela, quanto mais se aprofundam as pressões de Washington, maiores têm sido os investimentos e a importação de petróleo por parte dos chineses.

4 Ver discurso de Xi Jinping, disponível em: <http://www.beltandroadforum. org/english/>. Acesso em: 20 out. 2019.

5 Cf. Tang (2016). 
Em suma, a diplomacia chinesa busca explorar as linhas de menor resistência, evitando confrontos diretos e se valendo dos vácuos abertos pela abrangente e por vezes errática política externa estadunidense. Por um lado, é imperativo preservar as relações com o hegemon, inclusive porque os Estados Unidos representaram, em uma década (2008-2017), um saldo acumulado comercial de 3,2 trilhões de dólares ${ }^{6}$ ao país oriental. Por outro lado, as crescentes capacidades geoeconômicas e geopolíticas chinesas proporcionam progressivamente maior independência e assertividade ao país na arena internacional.

\section{As relações sino-iranianas no contexto das sanções}

Poucos países possuíam poder político e meios econômicos para intensificar as relações com Irã no contexto das sanções. Além do peso geopolítico, Beijing está articulando uma nova arquitetura financeira global ${ }^{7}$ para lidar com as estruturas hegemônicas herdadas do sistema Bretton Woods, centradas em Washington. São notáveis, pois, os esforços do governo da China para dar curso a sua moeda (yuan), para projetar globalmente sua rede de bancos comerciais e de fomentos, bem como para consolidar seu embrionário sistema internacional de pagamento - o China International Payment System-CIPS, alternativa ao ocidental Society for Worldwide Interbank Financial Telecommunication (SWIFT). Além disso, o comércio e os investimentos chineses também servem como desafogo à isolada economia iraniana.

Nesse viés de aproximação, a diplomacia chinesa optava por não aderir às sanções unilaterais, mas apoiava aquelas aprovadas pelo Conselho de Segurança da ONU. A primeira rodada de sanções foi estabelecida em dezembro de 2006, impondo restrições às atividades comerciais vinculadas com o desenvolvimento do programa nuclear iraniano. A segunda rodada, de março de 2007, ampliou o congelamento de ativos do país, além de proibir

6 Ver estatística da década, disponível em:<https://www.statista.com/ statistics/263632/trade-balance-of-china/>. Acesso em: 20 out. 2019.

7 Assunto abordado mais detalhadamente em Pautasso (2015). 
a exportação iraniana de qualquer tipo de equipamento bélico. A terceira, de março de 2008, ampliou novamente o congelamento de ativos, afetando empresas, instituições e pessoas vinculadas ao programa nuclear. A quarta rodada, de junho de 2010, proibiu a venda de várias categorias de armamentos pesados para o Irã, instaurou rituais de inspeções às cargas iranianas destinadas a outros países e ampliou, novamente, a lista de instituições afetadas pelo congelamento de ativos. Como pode-se claramente perceber, as restrições que afetaram diretamente a indústria energética iraniana não foram as multilaterais, aprovadas com aval chinês no Conselho de Segurança da ONU, mas sim as unilaterais, aplicadas pelos Estados Unidos e pela União Europeia.

Com o acirramento das tensões entre o Irã e as potências ocidentais, a China assumiu o protagonismo na condição de parceira estratégica de Teerã. Do ponto de vista comercial, o isolamento do Irã alavancou a corrente de comércio com a China, passando de 6,16 bilhões de dólares, em 2004, para 49,3 bilhões, em 2014, com considerável queda, para 32,3 bilhões, em 2015, no contexto das negociações que culminaram no JCPOA. Em 2004, a China era destino de 7,4\% das exportações e origem de 5,6\% das importações iranianas, passando, em 2014, para 49\% e 45\%, respectivamente. Em 2014, cerca de $75 \%$ das exportações iranianas para a China eram de petróleo, 6,3\% de minério de ferro, dentre outras consideráveis percentagens de derivados de hidrocarbonetos e matérias-primas. As importações iranianas à China eram compostas de bens processados, sobretudo máquinas e equipamentos eletrônicos (28\%), têxteis e calçados (10\%), veículos automotivos e peças $(8,6 \%)$ e plásticos e derivados $(6,8 \%)$, entre outros ${ }^{8}$. Ao longo desse período, com exceção de 2015 o superávit comercial do Irã foi significativo, totalizando no período 68,69 bilhões de dólares, tornando-se crucial para o país enfrentar o período de sanções (cf. tabela 1).

8 Dados do Atlas do Observatório da Complexidade Econômica, disponíveis em:<https://atlas.media.mit.edu/en/>. Acesso em: 20 out. 2019. 
Diego Pautasso, Tiago Soares Nogara, Augusto Gabriel Colório E Victor LeÃo Wobeto

Tabela 1 - Balança comercial do Irã com a China (em US\$ Bilhões)

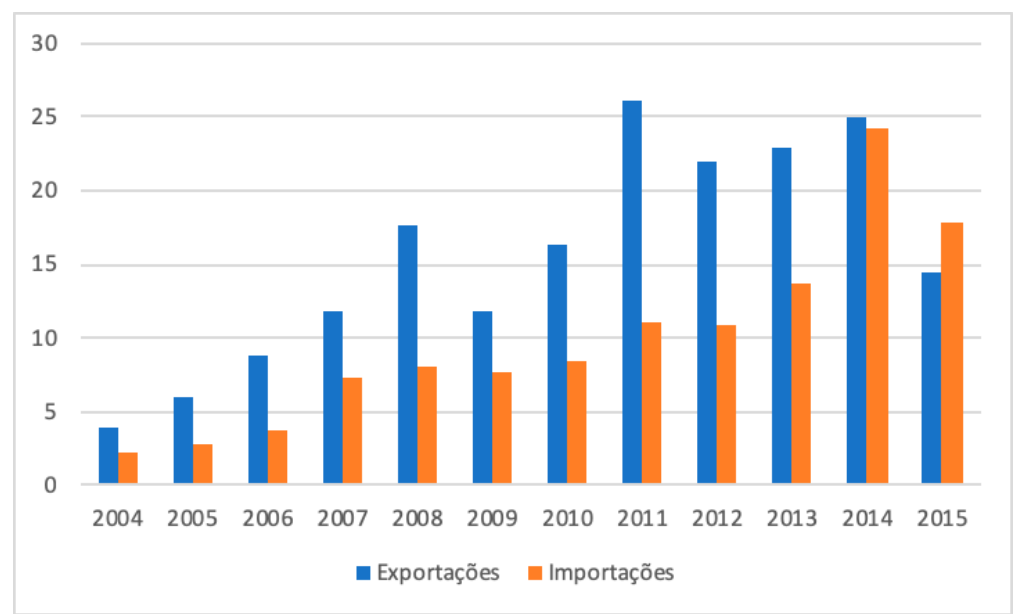

Fonte: OEC (2018).

Ressalte-se que, na última década (2007-2017), as importações totais de petróleo da China saltaram de 3,2 para 8,4 milhões de barris por dia' ${ }^{9}$, se tornando um evidente desafio para a manutenção da segurança energética. Contudo, o Irã, em 2014, era o sexto maior fornecedor de petróleo para a China, correspondendo a cerca de 9\% do total importado, contra 16\% da Arábia Saudita, o principal fornecedor. ${ }^{10}$ A corrente de comércio da Arábia Saudita com a China, em 2014, foi de mais de 64 bilhões de dólares ${ }^{11}$. Em outras palavras, Beijing tem em Riad seu principal fornecedor global de petróleo e seu principal parceiro comercial do Oriente Médio, sem que Riad tenha da China a mesma dependência que possui, hoje, Teerã. Com efeito, essa situação faz com que a diplomacia chinesa busque aprofundar as relações bilaterais com o Irã, mas sem descuidar do seu rival regional, a Arábia Saudita.

9 Ver base de dados estatísticos da CEIC Data. Disponível em: <https://www. ceicdata.com/en/indicator/china/crude-oil-imports $>$. Acesso em: 20 out. 2019. 10 Dados da Statista, disponíveis em: <https://www.statista.com/ statistics/221765/chenese-oil-imports-by-country/>. Acesso em: 20 out. 2019. 11 Conferir nota de rodapé 12 . 
Além do campo econômico, as relações sino-iranianas também se intensificaram no campo diplomático. Enquanto a pressão internacional recrudescia sobre Teerã, Beijing e Moscou incluíam, em 2005, o Irã como membro observador da Organização para a Cooperação de Xangai (OCX). Em 2008, o país médio-oriental anunciou oficialmente a sua intenção de integrar permanentemente a organização, visando três objetivos: I) participar dos processos de integração regional; II) ampliar sua projeção para além da região; III) escapar às sanções internacionais (SCITA, 2018). No entanto, a adesão do Irã requer certa concertação entre Beijing e Moscou, pois enquanto a China demonstra interesses estritamente pragmáticos com Teerã, os russos dividem interesses estratégicos e energéticos mais amplos na região do Cáspio e da Ásia Central, onde os iranianos possuem considerável influência.

Por um lado, é mister destacar que as relações da China se intensificaram com praticamente todos os países do mundo, em função do aumento de seu peso na produção e na demanda globais. Por outro, é evidente que a intensificação das relações sino-iranianas se deu também em consequência das sanções impostas pelos Estados Unidos e pela União Europeia (DOLATABADI; ZAREI, 2018). Simultaneamente, a diplomacia chinesa mantém sua orientação de se opor à proliferação nuclear, convergindo com decisões tomadas no âmbito do Conselho de Segurança, mas defende uma solução negociada para o conflito, preservando seus interesses estratégicos junto ao Irã, sobretudo no campo energético. É uma gestão diplomática que atenta, contudo, à conciliação da interdependência entre China e Washington, no âmbito global, e entre China e Riad, no âmbito regional.

\section{Considerações finais}

As relações sino-iranianas são diretamente condicionadas pela atuação dos Estados Unidos. Essa triangulação envolve interesses diversos e, por vezes, contraditórios. A China se preocupa com sua segurança energética, diante do controle estadunidense sobre parte expressiva das reservas energéticas globais. Nesse sentido, os hidrocarbonetos do Oriente Médio possuem importância 
Diego Pautasso, Tiago Soares Nogara, Augusto Gabriel Colório E Victor LeÃo Wobeto

estratégica, com destaque para as reservas do Irã e da Arábia Saudita. Assim, Beijing impulsiona as relações com Teerã, aproveitando-se da sua situação de isolamento, mas sem comprometer as relações com Riad. Da mesma forma, a diplomacia chinesa conduz as relações com o Irã sem colocar em risco a interação com as demais potências no âmbito do Conselho de Segurança da ONU, tampouco sua interdependência econômica com os Estados Unidos.

Essa condução pragmática da política externa chinesa pode ser uma das explicações para Washington ter recuado do cerco sobre o Irã - além dos interesses sobrepostos da indústria petrolífera e do complexo militar, entre outros. De todo modo, a ruptura unilateral do acordo em 2018 por parte dos Estados Unidos, sob a direção de Trump, atendeu, provavelmente, não apenas à narrativa de campanha do republicano, mas às relações estreitas deste com Israel e Arábia Saudita, bem como às inclinações de Teerã no contexto da guerra na Síria. Nesse cenário, a China tem aprofundado novamente a sua presença no Oriente Médio, inclusive realizando importações de petróleo iraniano lastreados em yuan e se apresentando na condição de um grande player na região. No quadro de conflitos e hostilidades, a iniciativa de integração eurasiática da Nova Rota da Seda pode ser por demais atrativa aos países da região.

Por fim, Washington recrudesce sua proeminência militar, enquanto sua capacidade de garantir a governança mundial a partir de instituições e da maior eficiência produtiva declinam. Como sugere Todd (2003), o aparelho militar estadunidense superdimensionado é necessário, mas insuficiente para manter a extração da renda planetária - um "tributo" que sustenta os déficits. Isso aprofunda clivagens típicas dos períodos de transição sistêmica, com tensões entre o hegemon e potências emergentes, projetos de desenvolvimento, instituições multilaterais e alinhamentos de poder alternativos para estabilizar a ordem mundial. Frequentemente, ações políticas e conflitos geram desdobramentos não-calculados, e, num contexto internacional disfuncional e com potencial disruptivo, acabam por precipitar transformações regionais e sistêmicas. 


\section{REFERÊNCIAS}

BANDEIRA, L. A. M. A desordem mundial. Rio de Janeiro: Civilização Brasileira, 2016.

A segunda Guerra Fria. Rio de Janeiro: Civilização Brasileira, 2013.

Formação do império americano. Rio de Janeiro: Civilização Brasileira, 2005.

DOLATABADI, A. B.; ZAREI, R. The Future of Iran-China Relations: an alliance or pure cooperation? Comparative Politics, Moscou, v. 9, n. 1, p. 60-73, 2018.

DORRAJ, M.; CURRIER, C. L. Lubricated with oil: Iran-China relations in a changing world. Middle East Policy, Wahsington, v. 15, n. 2, p. 71, 2008.

GAIETTA, M. The Trajectory of Iran's Nuclear Program. New York: Palgrave Macmillan, 2015.

GLADSTONE, R.; CASTLE, S. Global Network Expels as Many as 30 ofIran's Banks in Move toIsolate Its Economy. The New York Times, [online], 15 mar. 2012. Middle East.

HAROLD, S. W.; NADER, A. China and Iran: Economic, Political, and Military Relations. Santa Monica, CA: RAND Corporation, 2012.

HONG, Z. China's Dilemma on Iran: between energy security and a responsible rising power. Journal of Contemporary China, Denver, v. 23, n. 87, p. 408-424, 2014.

HUA, L. The Iran Nuclear Issue and China's Diplomatic choice. China International Studies, Beijing, n. 5, p. 92 - 103, 2006.

KISSINGER, H. Ordem Mundial. São Paulo: Objetiva, 2015.

LAMPREIA, L. F. Aposta em Teerã: o acordo nuclear entre Brasil, Turquia e Irã. Rio de Janeiro: Objetiva, 2014.

LAUB, Z. International Sanctions on Iran. Council on Foreign Relations, [online] 15 jul. 2015. Disponível em:<https://www.cfr.org/backgrounder/ international-sanctions-iran>. Acesso em: 19 dez. 2018.

LOSURDO, D. A linguagem do Império. São Paulo: Boitempo, 2010.

MONTE, J. China e África: a política de Pequim para o continente africano. Meridiano 47. Brasília, v. 11, n. 116, 2010.

OEC - Observatory of Economic Complexity. What is the trade balance for Iran to China? (2004-2015). Observatory of Economic Complexity, [online], 2018. Disponível em: <https://atlas.media.mit.edu/en/visualize/ line/hs92/show/irn/chn/all/2004.2015/>.Acesso em: 19 dez. 2018. 
Diego Pautasso, Tiago Soares Nogara, Augusto Gabriel Colório E Victor LeÃo Wobeto

PAUTASSO, D. A China na nova arquitetura geoeconômica global e o caso do Banco Asiático de Investimento em Infraestrutura. Meridiano 47, Brasília, v. 16, p. 12-19, 2015.

SCITA, J. Iran and the SCO: A Long Political Gestation. The London School of Economics and Political Science, [online], 2018. Disponível em: <http://blogs.lse.ac.uk/mec/2018/08/30/iran-and-the-sco-a-longpolitical-gestation/>. Acesso em: 04 jan. 2019.

TAN, H. China Tilts to Iran as Xi Caps Visit With 17 Accords. CNBC, [online], 25 jan. 2016. Politics.

TODD, E. Depois do Império. Record: Rio de Janeiro, 2003.

YORDAN, C. The Imperial Turn: Analyzing Post-9/11 American Foreign Policy Through the Prismof 1898. Revista História Actual. Cádiz, v. 4, n. 4, p. $27-44,2006$. 